\title{
Influence of town-planning on social and economic progress of the subject of the Russian Federation in aspect of regional management
}

\author{
Tatyana Miroshnikova ${ }^{1}$, Natalia Taskaeva ${ }^{2, *}$ \\ ${ }^{1}$ Vladivostok State University of Economics and Service, Gogol str., 41, Vladivostok, 690014, Russia \\ ${ }^{2}$ Moscow State University of Civil Engineering, Yaroslavskoe shosse, 26, Moscow, 129337, Russia
}

\begin{abstract}
The aim of research is to form a method allowing estimating the influence of town-planning on social and economic development in the region. The article presents the natural - territorial and socio-economic conditions that determine urban development. Authors examine the natural conditions in conjunction with the planning factors as a priority when implementing management actions on the socio-economic situation of the region. Complex evaluation of natural factors allows to take into account their impact on the quality of the created urban environment, and to predict possible scenarios of spatial strategy. The article examines the problems of formation of transport and logistic center of the city district integrated into the Asia-Pacific region. The strategic goal of development of the transport sector is the development of a balanced transport system. In the process of research was used analytical method for the processing of statistical and accounting documentation of the Administration of the city district. The research methodology involves use of information approach which in turn requires the use of such research methods as vertical, horizontal and comparative analysis.
\end{abstract}

\section{Introduction}

One of the priorities of State regulation of the Russian economy in the framework of a strategic approach to regional management is to assess factors affecting the urban environment and the level of socio-economic development of the regions that require analytical processing of indicators, revealing major trends and areas problem of concern regional status.

Presented analytical method is useful in relation to the various regions, as it provides the possibility to modify the performance indicators depending on the data found in the official statistical reporting. The analytical results obtained can be used in the formation of project activities in the municipal government, in order to improve the effectiveness of

\footnotetext{
* Corresponding author: natalia.taskaeva@yandex.ru
} 
management actions on regional processes that allows creating tools to enhance the effectiveness of controlling impacts on socio-economic development.

The aim of this study is to form a method of analyzing the indicators, allowing to estimate the influence of town-planning on social and economic development and to identify the main trends of strategic management of territory. The implementation set in the study objectives was carried out using empirical material in the region of the Russian Far East.

As the solution for tasks on the efficiency of the regional management reviewed the question of actuality of providing of the integrated politics considered in area of strategic decision of transport problems the relevance of an integrated policy in the field of strategic transport solutions.

The object of the study discusses urban ecology and the socio-economic situation of the Vladivostok municipal district as a subject of strategic development.

\section{Methods}

The methodology is based on the following provisions:

- using the analytical approach to the choice special purpose indexes;

- comparison of indexes and analysis of their dynamics, realization of comparative analysis.

Each of these metrics can be exposed by using the method of horizontal analysis that to identify the trend in its change; comparison method and index method.

The Vladivostok municipal district, as the most populated part of Primorsky Krai, is a rapidly growing and economically progressive region in the Far East. The following key factors determine the relevance of formation in the area of transport and logistics center: being in a densely populated Asia-Pacific region, which is an attractive market, favourable transport position at the crossroads of transit routes, the presence of a major port.

In the framework of urban planning the creation of an effective transport system is a prerequisite for modern development, preserving and improving the quality of the natural environment, improve the welfare of the population, which is most actual in the current economic conditions.

The Vladivostok municipal district as the most populated part of Primorsky Krai, is a rapidly growing and economically progressive region in the Russian Far East. Vladivostok municipal district is the territory of the two Peninsulas Muravyov - Amursky and Peschany Peninsula and about 50 Islands of the Bay of Peter Velikiy. In the planning and management of urban, industrial and civil construction should take into account the presence of a large number of transport and industrial enterprises, peninsular geographical position of the city, mountains relief. One of the most important policy tasks of Russia is to create a center of Russian political and economic influence in the Asia-Pacific region.

The current stage of development of the urban transport system of Vladivostok is characterized by several distinguishing features due to natural-geographical, socioeconomic and organizational-managerial factors. Highlight the factors determining the state of the transport system of Vladivostok urban district [1-23].

1. The natural - geographical factors.

On the one hand, it should be noted strategically advantageous geopolitical position, which is expressed in close proximity to the Asia-Pacific region. It refers to important competitive advantages of the city of Vladivostok as an additional incentive for state support of development of the city, as well as a determinant of high investment attractiveness for countries of the Asia-Pacific region.

On the other hand, Vladivostok is characterized by a combination of adverse natural and geographical conditions, difficult transport support transportations. This is due to the 
peninsular position of the city in a relatively small area; very irregular coast with bays and coves; difficult mountainous terrain, river valleys; frequent changes of weather conditions, the annual emergency situations (heavy rains and snowfalls), destroying the road surface.

2. Socio-economic and organizational-managerial factors hindering effective development of urban transport system. These include:

- the lack of a common General scheme of development of transport infrastructure of the site based on future traffic volumes including the development of port facilities, rail entrances and port railway stations, main roads;

- the lack of adjustment of outdated General plan of the city;

- the absence of a mechanism for land reservation for the development of main streets and roads and their actual reservations in the entrance to the port and industrial zone;

- unplanned development of residential, public and business zones of the city, including in areas of a proposed new trunk roads and access roads;

- slow pace of construction of access roads to the ports because of the weak financial and institutional reasons.

Thus, the strategic decision of transport problems of Vladivostok should be focused on the implementation of integrated policy of development of its urban environment. This approach is a necessary condition for achieving a high quality transport service, the most efficient use of urban opportunities and resources, increased use of urban areas.

The development of a transportation system of the municipal district should be aimed at ensuring sustainable socio-economic growth of the region. The task of the development of the transport sector is to upgrade and expand the freight and passenger transport vehicle fleet.

We will present the analysis of freight and passenger traffic of Vladivostok municipal district by type of transport [2].

Table 1. Volume of the shipped cargoes of all types of transport (million $t$ ).

\begin{tabular}{|c|c|c|c|c|c|c|}
\hline Type of transport & 2010 & 2011 & 2012 & 2013 & 2014 & 2015 \\
\hline Transport & 30.38 & 32.90 & 35.35 & 36.10 & 38.00 & - \\
\hline including & & & & & & \\
\hline rail transport & 14.5 & 15.8 & 15.2 & 15.1 & 13.9 & - \\
\hline road transport & 4.7 & 5.3 & 7.1 & 6.5 & 8.8 & 8.05 \\
\hline sea transport & 11.18 & 11.8 & 13.05 & 14.5 & 15.3 & 14.87 \\
\hline
\end{tabular}

According to data of the table the amount of the shipped goods of all types of transport increased from 2010 for 2014 by $25 \%$ that in absolute terms amounted to 7.6 million tons.

In 2014 in comparison with last year the volume of the transported freight increased by $5.2 \%$ that in absolute terms amounted to 1.9 million tonnes.

The largest share in the structure of transported goods for 2014 is the marine mode of transportation occupies a sea transport mode $(40.3 \%)$. In dynamics for the five-year period the share of the goods transported by the sea message increased by $3.5 \%$. Also is changed the share of road transport. So, in 2014 its share is $23.2 \%$, while in 2010 it amounted to equated $15.5 \%$. Proportion of freights transported by railway transport in 2014 decreased by $11.2 \%$, and comprises $36.6 \%$. Thus, there is a tendency to increase automobile and marine traffic, and decrease in the share of transportations of the railroad freight. 


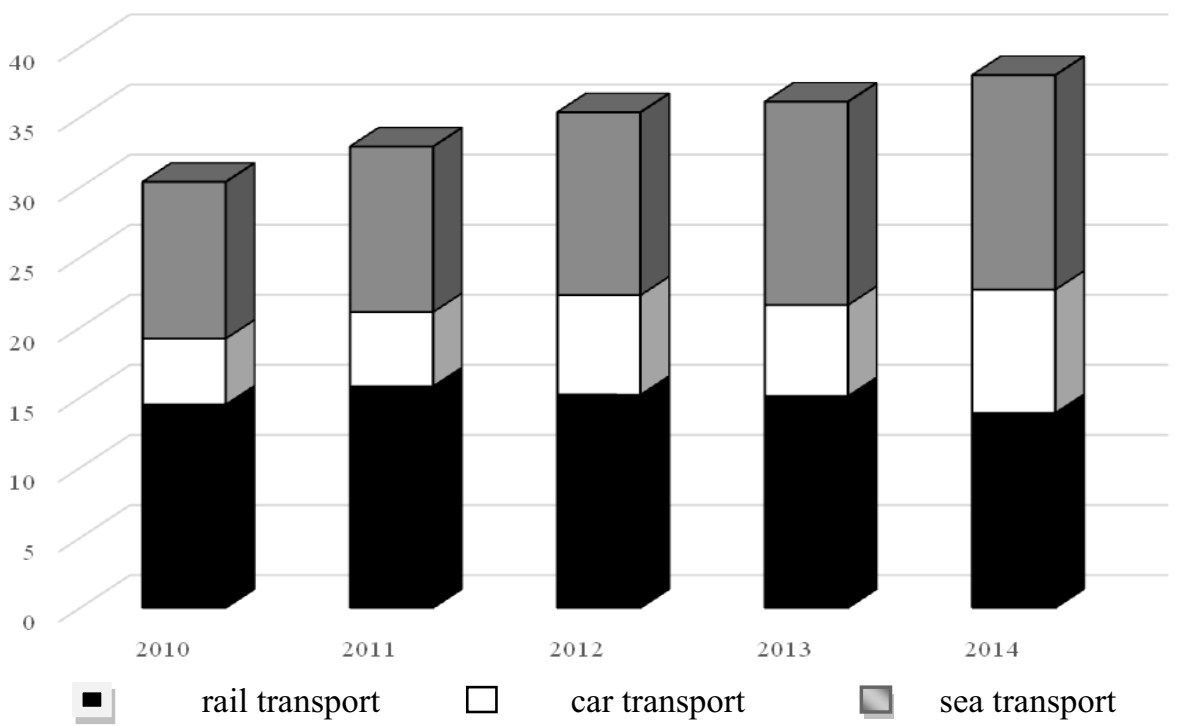

Fig. 1. The Number of passengers carried in the city by types of transport, thus. pers.

The development of road transportation, railway and port infrastructure of the transport system allows providing possibility of regular and uninterrupted transportation, socioeconomic development in the area, and also contributes to improving service quality and reducing time of freight and passenger transportation.

Low handling capacity of the transport road grid not matching the growth of motorization and traffic load. In this city there is a need for a large capital expenditure for a fundamental solution to the problems of development of road and transport infrastructure, with the existing location of buildings and structures. For Vladivostok priority value has sustainable development of the sea transport hub.

Table 2. The volume of transfer of goods in ports, million t [3].

The volume of transfer of goods in ports

\begin{tabular}{|c|c|c|c|c|c|}
\hline 2010 & 2011 & 2012 & 2013 & 2014 & $2015^{*}$ \\
\hline 11.18 & 11.8 & 13.05 & 14.5 & 15.3 & 9.5 \\
\hline
\end{tabular}

* - 9 months 2015.

According to table 6 and figure 5, the volume of transshipment of cargo in ports by 2014 amounted to 15.3 million tonnes, which is $36.8 \%$ higher than in 2010 and $5.5 \%$ above 2013 However, there are some factors that making harder the effective development Vladivostok ports. 


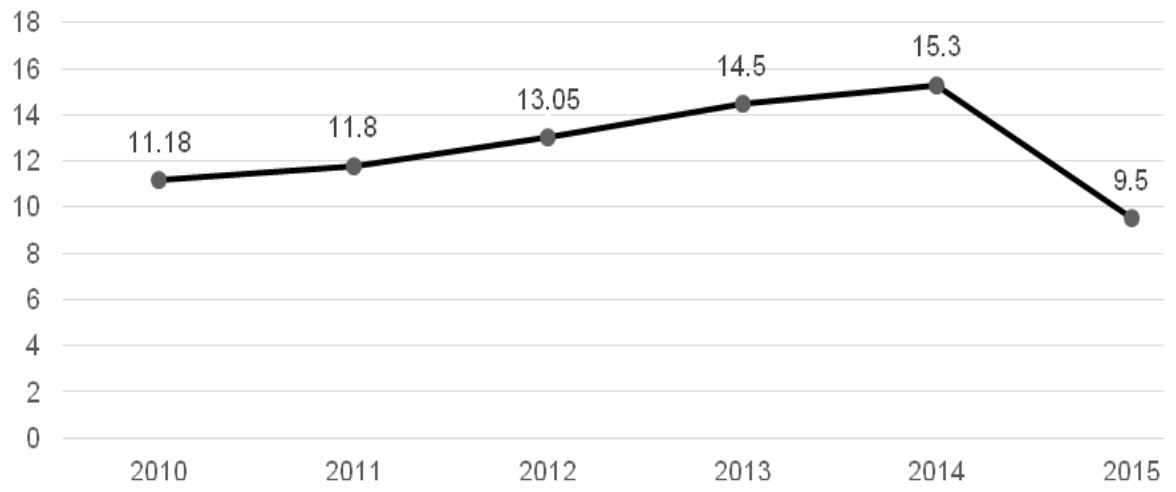

Fig. 2. The Volume of transshipment of cargoes in ports, mln t.

In modern conditions of violation of town-planning ecology the development of alternative environmentally friendly transport modes of transport by passenger vessels and ferry boats is a perspective development tool of developing a balanced transport system of the city. The development of port facilities in Vladivostok are limited by the fact that the port is surrounded by urban areas.

Insufficient development of Maritime communication hinders the development of the city and agglomerations area. Tourist and recreational potential of the sea city is not implemented without organized Maritime traffic. For the sustainable operation of ports required well-developed system of port and port stations, providing a part-time job sorting and routing of cargo distribution in the cargo areas of the port. However, the relief from oppression of territories, none of the stations on the immediate approaches to Vladivostok is unable to perform the functions of pre-port stations.

In terms of investment in fixed capital Vladivostok is in the second place among the regional centers of the Far Eastern Federal district, giving the city of Khabarovsk. The main source of investment are the budget funds, mainly from the Federal budget, the budget of the city is scarce, incomes are generated mainly by taxes $(51.2 \%)$ [4].

In 2015 the decline of $29.9 \%$ of the volume of works by the form activity "Construction" for large and medium organisations in comparison to 2014. In 2016, a decrease of $33.3 \%$ by 2015 the volume of works by the form activity "Construction" for large and medium organizations.

The actual value of "Annual net increase in the value of fixed assets of all economic entities of all forms of ownership in the city" for the period 2012-2013 show a positive trend ahead of forecast values [5].

Fixed assets proportion value of all economic entities of all city ownership forms in the fixed assets cost on the territory of Primorsky Krai takes different values in the analyzed period, reaching the highest value in 2010 (32.78\%), the lowest in $2012(16.12 \%)$. Investments in fixed capital organizations in the city of Vladivostok in 2014 amounted to 65993.9 million ( $87.0 \%$ by the end of 2013), including large and medium-sized enterprises 52688,8 million. Public funds are dominated by of $62.1 \%$ in the structure of sources of investment [7].

There are a large number of programs affecting the value of the urban development plan, long-term target program "Development of Vladivostok as international cooperation center in the Asia-Pacific region", State program "Development of transport complex of Primorsky Krai", which is missing or not fully funded [8]. 
Overall review of the implementation programs in the period 2010-2014 leads to the conclusion that the program-target method as tool of realization of strategy of socioeconomic development of Vladivostok is currently being used inefficiently.

The structure of the annual net increase in the value of fixed assets of all businesses in the Vladivostok city district of Primorsky Kari for the period 2010-2013 is shown in Figure 3.

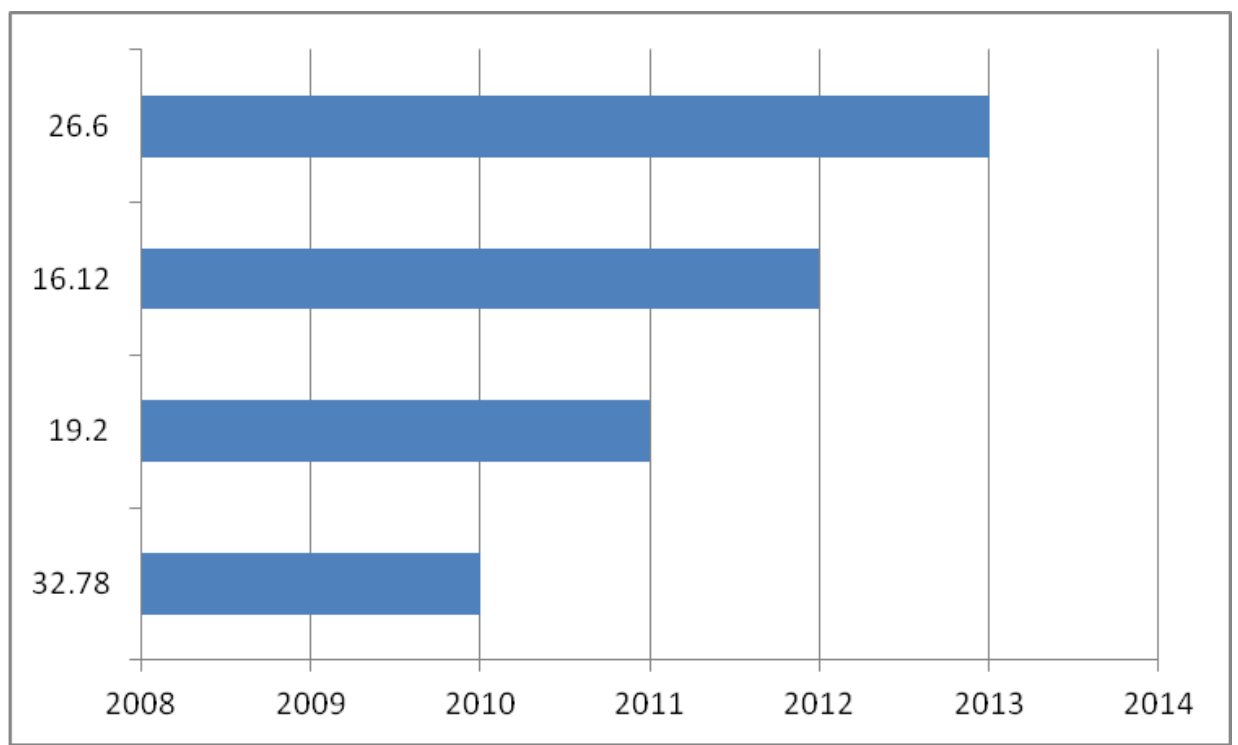

Fig. 3. The Structure of the annual net value of fixed assets of all businesses in the Vladivostok city district of Primorsky Krai for the period 2010-2013 (\%).

In 2015, investments in fixed capital of large and medium-sized enterprises in the economy of the city of Vladivostok amounted to $74.9 \%$ (44.9 billion rubles) in 2014 [9].

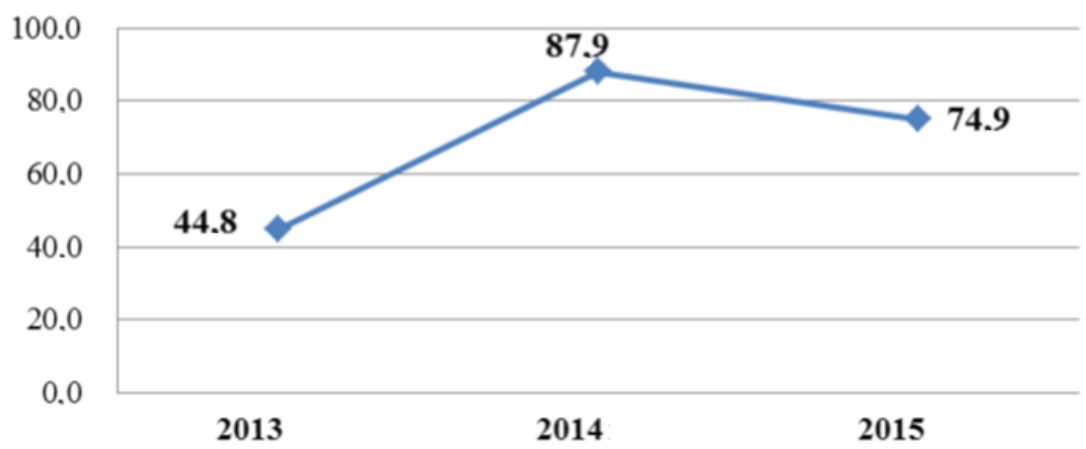

Fig. 4. Dynamics of investments into a fixed capital of the large and average organizations in percentage by the similar period of the last year.

In January - September 2016, investment in fixed capital of large and medium-sized enterprises in the economy of the city of Vladivostok amounted to $80.8 \%$ (23.3 billion rubles) January - September 2015.

Of the total investment in 2015 in fixed capital of large and medium-sized organizations: 
- investment in buildings and structures declined in 2014 and amounted to $46,0 \%$ of the total volume of investments in fixed capital;

- investment in housing amounted to $6.9 \%$ of the total volume of investments in fixed capital;

- investments in machinery, equipment, vehicles, fixtures and fittings amounted to $44.9 \%$ of the total volume of investments in fixed capital.

The largest share in investments in fixed capital took investments by type of activity "Transport and communication" at $35.9 \%$.

Of the total investment in 2016 in fixed capital of large and medium-sized organizations:

- investment in buildings and facilities accounted for $48.9 \%$ of total investment in fixed capital;

- investment in housing amounted to $13.1 \%$ of the total volume of investments in fixed capital;

- investments in machinery, equipment, vehicles, fixtures and fittings was $35.8 \%$ of the total volume of investments in fixed capital.

The largest share in investments in fixed capital took investment activities "Transport and communication" - by $26.8 \%$ and "Operations with real estate, rent and granting of services" $-26.6 \%$.

In the period from 2010 to 2014 , the highest expedictures was observed in the transport services to the population and came up to 38151.18 rub per capita of Vladivostok municipal city.

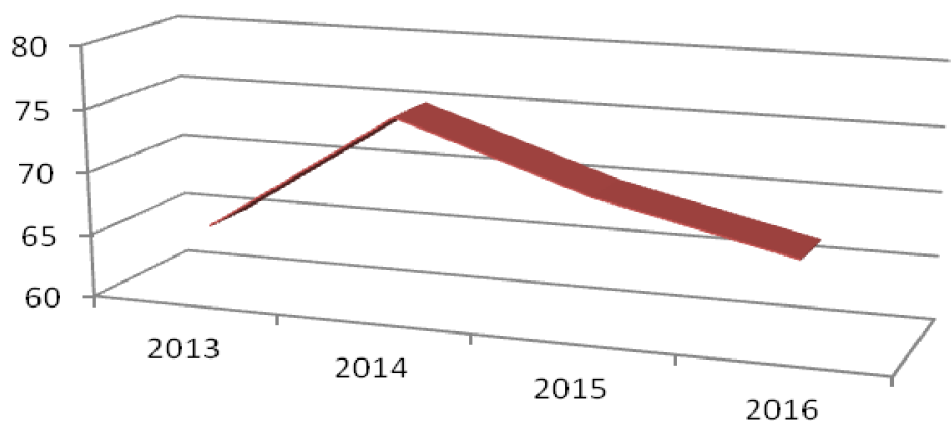

Fig. 5. Dynamics of volume of works by the form activity ' Construction ', pace of growth, \% [9].

Vladivostok is one of the major economically developed cities of the Russian Far East. The city is a major transportation hub, through which sea, rail, road and air traffic flows. The considered city and the economically-oriented South part of Primorskii Krai have considerable potential in the sphere of development of transport infrastructure and transit flows, and to support manufacturing industries, fisheries and others.

Vladivostok as the capital of the province, takes the leading place in economy of Primorye territory. [8] In the city was 24.6 per thousand enterprises, accounting for 57 percent of all enterprises, firms and organizations working in the Primorsky Krai. [9]

Table 3. Share of the city of Vladivostok on the selected indicators in accordance with the priority specializations [9].

\begin{tabular}{|c|c|c|c|}
\hline Specialization & Vladivostok & $\begin{array}{c}\text { Primorsky } \\
\text { Krai }\end{array}$ & $\begin{array}{c}\text { Far East federal } \\
\text { district }\end{array}$ \\
\hline Transport and logistic center & & & \\
\hline $\begin{array}{l}\text { Goods turnover of seaports } \\
\text { transport, thousand tons }\end{array}$ & 14500 & 73848 & 144800 \\
\hline
\end{tabular}




\begin{tabular}{|l|l|l|l|}
\hline \multicolumn{1}{|c|}{ Industrial center } & & \\
\hline $\begin{array}{l}\text { Shipped self-produced goods, } \\
\text { executed works and services with } \\
\text { own forces on the large and } \\
\text { average organizations, billion } \\
\text { rubles Service center }\end{array}$ & 110.501 & 212.094 & 1192.289 \\
\hline $\begin{array}{l}\text { Retail trade turnover billion } \\
\text { rubles, }\end{array}$ & 129.797 & 247.232 & 865.313 \\
\hline $\begin{array}{l}\text { Volume of paid services to the } \\
\text { population, billion rubles }\end{array}$ & 65.235 & 136.916 & 494.946 \\
\hline
\end{tabular}

\section{Results}

Logistics and transport are essential for the development of the economy of Primorye, the Far East and Russia. Currently a bill is adopted on the creation of a "Free port". Singapore and Hong Kong, have become megalopolises of the world level, largely due to the regime of free ports. Create a unique for the region "Porto-Franco" will improve the logistics and transport communication between Russia and Asia. The creation of an effective transport system is a prerequisite for modern development, improve the welfare of the population, which is most relevant in the current economic conditions [12].

Vladivostok is a transportation hub, largely determines the state of the economy and other areas of the Far East. This provides a concentration of about 13,6\% of the value of fixed assets, $9.2 \%$ of the employed population of the region. The total gross regional product generated in the region, about 20 percent is provided by transport. The structure of the types of transport the level of turnover can be summarized as follows: the share of maritime transport accounts for 57.8 percent of all transportations, train - of 41.85 , automotive -0.25 and air transport -0.11 percent.

Naval ships of Far East sea shipping company annually visit more than 300 ports in 60 countries. The largest joint enterprise carries out foreign and cabotage in the North of the Far East and the Arctic. Naval fleet are represented by different types of vessels. A significant part of their work in the mode of freight on international routes [8].

The relevance of formation in the area of transport and logistics center is determined:

- by finding it in the densely populated Asia-Pacific region, which is the market;

- favorable transport situation at the crossroads of transit routes;

- the presence of a major port can accept vessels of almost any tonnage.

- In this regard, it is important to ensure smooth traffic flow by minimizing costs.

This study includes analysis of external and internal factors that facilitate and impede effective transport system in the city Vladivostok, as well as development of recommendations about decrease in influence of the factors acting negatively on the process of creation of creating a balanced system.

Considering Vladivostok city agglomeration extending from the North to the south for more than $60 \mathrm{~km}$, existence of the torn-off remote territories (islands, settlements) are absent basic means of transport (speedway).

The main measures within effective urban-planning providing development of infrastructure of a railway transport and transportations are:

- construction of new roundabout ways within city agglomeration;

- limit the volume of a cargo transportation through seaports;

- increase the number of sent trains in the suburban message and increase the speed of their movement. 
An analytical study identified key socio-economic problems impeding the development of the city. The high degree of depreciation of fixed assets utilities and engineering infrastructure; lack of financial resources budgetary and extra-budgetary; the demographic situation (population decline: the mortality rate exceeds the birth rate); lack of qualified personnel for the implementation of separate directions of development of the city.

\section{Discussion}

Thus, the study performed with the involvement of methods of horizontal and vertical analysis comparison, in the framework of the analytical approach were obtained the following results. On the basis of performed studies concluded that Vladivostok has a high partial-utilized transport capacity. The strategic goal of development of the transport sector is the creation of transport-logistics centre integrated into the countries of the Asia-Pacific countries and bringing transport infrastructure to meet the needs of development of economy and social sphere. Using analytical method the basic tendencies and problems of transport development in the region. Using the method of comparative analysis based on statistical and reporting data analysis was carried out.

The problem of transport complex of the region is the low level of development of transport infrastructure; a significant degree of wear and tear of equipment, insufficient funding, low interest of investors due to the low profitability of the projects.

As possible ways to solve problems and improve the efficiency of regional management proposed the formation of an effective system for attracting corporate investments from Asia Pacific. A striking example is the inflow of direct foreign investments in the amount of 1153.4 million dollars from Japan to the one of the largest joint projects with Japanese investors - the construction of a plant for the liquefaction of natural gas "Vladivostok SPG," ensuring a favorable investment climate [13,23]. It can be stated that the most significant external factors influencing the development of the Vladivostok are:

- the implementation of major investment projects, such as

- the formation of transport-logistics centre, the revival centres of modern shipbuilding;

- the creation of a "Free port of Vladivostok" (Vladivostok transport node that defines the state of the economy).

\section{Conclusions}

In modern conditions, violations of town-planning ecology the development of alternative environmentally friendly modes of transport by passenger ships and ferries is a perspective development tool of the balanced transport system of the city. The development of port facilities in Vladivostok are limited by the fact that the port is surrounded by urban areas. Inadequate development of Maritime communication hinders the development of the city and agglomerations. Tourist and recreational potential of the sea city is not implemented without organized Maritime traffic.

Economic and territorial development of Vladivostok requires the development of intermunicipal cooperation, coordination of interests of the territories, as well as trends of their development $[14,22,24]$.

With the aim of developing the city of Vladivostok on the strategic direction of "developing efficient economy" it is reasonable to create modern center of tourism in Vladivostok and the surrounding territory. Competitive advantages of the island's "Russkiy" - advantageous geographical location, availability of land suitable for development, clean sea, make Iland a convenient place for placing of objects of recreational 
appointment. Positioning the city as a competitive centre in the Asia Pacific region is defined by the existing recreational potential, originality and uniqueness of the city.

\section{References}

1. http://www.vlc.ru/administration/the-list-of-information-systems/

2. Primorsky Krai (Primorskstat, Moscow, 2015)

3. http://www.morport.com

4. http://primamedia.ru/news/economics/19.02.2014/337439/ob-em-inostrannihinvestitsiy-v-ekonomiku-primorya-uvelichilsya-v-chetireraza.htmlhttp://primamedia.ru/news/economics/

5. http://www.primorsky.ru/

6. http://primamedia.ru/news/economics/19.02.2014/337439/ob-em-inostrannihinvestitsiy-v-ekonomiku-primorya-uvelichilsya-v-chetireraza.htmlhttp://primamedia.ru/news/economics/

7. http://www.vlc.ru/city/social economic development/http://www.vlc.ru/budget/

8. http://www.vlc.ru/city/social_economic_development/

9. G.V. Guttman, A.A. Miroyedov, S.V. Fedin, Management of regional economy (Moscow, 2002)

10. I.I. Melamed, Strategy of development for the Far East for Russia (Modern economy and right, Moscow, 2008)

11. http://www.gks.ru/dbscripts/munst/munst05/DBInet.cgi

12. http://primstat.gks.ru/wps/wcm/connect/rosstat_ts/primstat/ru/statistics/db/

13. http://dumavlad.ru/about/statisticheskaya-informatsiya

14. Updating of Strategy and the strategic plan of development of the Vladivostok city district till 2020 with prolongation of validity period till 2030 (VGUES, Vladivostok, 2015)

15. T.N. Matskevich, Problems of social and economic development of the region: monograph (Argus, Stavropol, 2004)

16. S.N. Yashin, E.N. Puzov, Finance and the credit, 123 (2006)

17. N.V. Kuznetsova, M.A. Perun, Management in Russia and abroad, 6 (2006)

18. Town planning for small communitie (D. Appleton and Company, NewYork, 2004)

19. E. Stein, N. Taskaeva, E. Chibisova, Procedia Engineering 165, 1410-1416 (2016)

20. I. Polyakova, E. Vasilyeva, Procedia Engineering 165, 1380-1387 (2016)

21. V.S. Morozov, N.N. Taskaeva, Man in India 96, 2009-2023 (2016)

22. An.B. Mottaeva, As.B. Mottaeva, International Journal of Applied Engineering Research 10, 43446-43449 (2015)

23. S. Paunović-Žarić, V. Radulović, E. Alihodžić-Jašarović, V. Murgul. Journal of Applied Engineering Science, 14(1), 140 - 147 (2016)

24. T.A. Verminskaya, V.Sh. Zinatullin, A.V. Kukhta, I.V. Rubtsov, E.Yu. Chibisova, Almanach of modern science and education 7, 37-39 (2008) 